www.jmscr.igmpublication.org

Impact Factor (SJIF): 6.379

Index Copernicus Value: 79.54

ISSN (e)-2347-176x ISSN (p) 2455-0450

crossrefDOI: https://dx.doi.org/10.18535/jmscr/v6i10.219

Journal Of Medical Science And Clinical Research

IGM Publication

An Official Publication of IGM Publication

\title{
Assessment of Retention of Skills with Simulator based Training among Anaesthesiology Residents
}

\author{
Authors \\ Jithumol Thankam Thomas ${ }^{1}$, Bhagyalakshmi $\mathbf{R}^{2}$, Rachel Cherian Koshy ${ }^{3}$ \\ ${ }^{1}$ Senior Resident, ${ }^{2}$ Associate Professor, ${ }^{3}$ Professor and HOD \\ Department of Anaesthesiology, Regional Cancer Centre, Trivandrum \\ Corresponding Author
}

Dr Jithumol Thankam Thomas

C/O M P Philip, Mundukottackal House, Chethackal P.O Ranni, Pathanamthitta District

Kerala, Pin code-689677, India

Mobile no- 09632094554, 9008069552

Email:drjithu88@gmail.com,punnoose_2006@yahoo.com

\begin{abstract}
Background and Aims: A continuing attempt in graduate education is to devise more effective methods to assess and train the residents. Life sized simulators are nowadays being used as a novel technique for this purpose. The aim of this study was to evaluate the effectiveness of simulator based training and retention of learnt skills among anesthesiology residents.

Methods: This interventional study was conducted on the 20 postgraduate ( $\mathrm{pg}$ ) residents in our institute, who were divided into 3 groups, based on their years of training - PG Level 1,2 and 3. Each participant was given 3 scenarios for simulation on Advanced Life Support(ALS) SIMULATOR which included A) Endotracheal intubation, B)Advanced care life support and C)Epidural technique. At the end of scenario, participants were debriefed and simulator based training provided. The study was then repeated after an interval of 4 weeks. The scores before and after simulator training was compared for each scenario. Also scores between the pg levels were compared. Statistical tests used were Kruskal-Wallis one way Analysis of variance (ANOVA) and Wilcoxon Signed Rank Test.

Results: A significant improvement in scores were noted after 4 weeks of the initial simulator training for all scenarios ( $p$ value of 0.000 for all 3 scenarios). While the more experienced final year residents outscored less experienced ones in scenarios $A$ and $B$, first years scored equally well as their seniors after simulator training for scenario $C$.
\end{abstract}

Conclusion: Simulator training can be effectively used to train and refine skills among residents and anaesthesiologists.

Keywords: Simulation, Anaesthesia, Residents, Training, Simulator.

\section{Introduction}

Anaesthetists routinely deal with high stakes situations and life threatening events, where the acceptable margin of error is very small. Such events demand exceptional skills and vigilance. This is why our speciality is often compared with the aviation industry. ${ }^{[1-4]}$ However within creasing pressure to use operating room (OR) time 
efficiently, opportunities for residents to learn and acquire skills in the OR are limited. Simulation provides an educational setting where anaesthesia residents, consultants and other healthcare professional as well, can acquire and refine skills $\&$ expertise necessary to recognize and manage critical scenarios, without endangering human lives.

Simulation is a technique by which real life scenarios are simulated using mannequins and other supporting tools, making the experience as realistic as possible in a fully interactive manner. ${ }^{[5]}$ Currently, full-size mannequin patients are used in most simulation centres, like Sim Man ${ }^{\circledR}$ from Laerdal and Human Patient SimulatorHPS II from METI $^{\circledR}$, to name a few.

\section{Methods}

The purpose of this interventional study was to evaluate the effectiveness of Simulator based training and retention of learnt skills among the 20 anesthesiology residents in our institute which is a tertiary care cancer hospital in South India.

After obtaining Institutional review board committee clearance, all anaesthesia residents training in our institute were enrolled. Based on their years of training in Anaesthesia they were divided into 3 groups. PG Level 1 included the first year postgraduates, PG Level 2 included the second years and PG Level 3 included the third (final) year postgraduates. Each participant was given 3 scenarios for simulation on Advanced Life Support SIMULATOR and Laerdal mannequin. The 3 scenarios chosen were A) Endotracheal intubation, B)Advanced care life support(ACLS) and $C)$ Epidural technique, considering that the participants of the study included final year postgraduates as well as recently joined first year postgraduate residents ( $<5$ months training) . A pilot simulation of the above scenarios were performed and a checklist was devised.

After an initial simulator orientation, the residents were provided the scenario and instructed to perform the task at hand.Their performance was assessed by 3 senior anaesthesia consultants who volunteered and were not involved in the study. The participants were rated according to the actions or steps intended(checklist) given in the proforma. They were given a score of 0 or 1 depending on whether the desired action was completed or not. The time taken for each step was also noted. If the desired action was not performed within the stipulated time, a score 0 was given. The total score was then calculated. All participants were instructed to verbalise loudly and clearly. At the end of the scenario, participants were debriefed and simulator based training was provided to them for each scenario.

The study was then repeated after an interval of 4 weeks to assess the retention of learnt skills. Here they were assessed by the same senior consultants who evaluated them previously.

Scores from the first test were compared to scores from the second test done after 4 weeks for each participant and analysed using Wilcoxon Signed Rank Test. Also, comparative scoring among different participants based on the years in training and experience was done using KruskalWallis one way Analysis of variance (ANOVA). All Demographic data was recorded as Frequency (percentage \%).

\section{Results}

In our study, a checklist was used to score residents. The final scores were inclusive of stepwise actions and verbalisation of these actions, and not just the final outcome. Residents could perform many actions listed on a checklist but fail to perform the most essential diagnostic or therapeutic ones. Residents were awarded a score of 0 or 1 depending on whether the action was performed or not and if it was performed within the stipulated time and verbalised loudly. Thus, scoring was made more easier for the raters and interrater variability was minimised.

A total of 20 participants were enrolled in the study. Among them 6 were first year residents, 7 were second year residents and 7 were final year residents. 
A significant improvement in scores were noted 4 weeks after the initial simulator training for all scenarios. A p value of $0.000(<0.05)$ was noted with all 3 scenarios among the residents. A wilcoxon signed rank test was used to compare and a paired $\mathrm{T}$ test was used to obtain the mean [Table 1].

The more experienced final year residents outscored less experienced ones in the simulated scenarios designed to assess their skills and ability to manage acute care situations. The initial pre training score was noted to be significantly higher for the third year and second year residents as compared to first years for scenario $A(p$ value 0.000 and 0.001 resp) [Table 2]. In regard to the overall improvement in score for scenario A, a significantly higher improvement was noted with first years as compared to second years and final years (p value 0.002 and 0.000) [Table 3 and 4]. The improvement in score for Scenario A was not statistically significant between second years and final years ( $\mathrm{p}$ value 0.117)[Table 5].Thus we ascertain that the first years benefited significantly more after training for scenario A as compared to second years and final years, who had more number of years of training .

In Scenario $\mathrm{B}$, the pretraining score was significantly higher for second years and final years as compared to first years( $\mathrm{p}$ value 0.002 and 0.000 ) [Table 2]. Following training a significant improvement in score was noted for all the residents. The improvement in score was statistically significant between first years and second years ( $p$ value 0.005 ), between first years and final years ( $p$ value 0.000) and between second years and final years ( $p$ value 0.028) [Table 5].

In scenario $\mathrm{C}$ also, the pre training score was significantly higher for final years and second years as compared to first years ( $p$ value 0.004 and 0.02) [Table 2].But the pre training score between second years and final years were not statistically different ( $\mathrm{p}$ value 0.977 ). Post 4 week training, while all pg levels did show significant improvement, no statistical significance was noted between the pg levels[Table 3 and 4].All pg levels fared equally well after the four week training. Thus it was observed that second years were as equally efficient as final years in epidural even before the training and first years too became as efficient as final years, post the simulator training. Junior postgraduates performed equally well as their seniors in epidural technique after 4 weeks of the initial training [Table 5].

We anticipated that the additional training and clinical experiences of senior postgraduates who were more familiar with emergency situations and confident with treatment of these conditions would have lead to higher scores for scenarios such as intubation and ACLS. Epidural technique showed significant improvement after simulator training among first years and thus simulation is a very effective method of training residents in regional techniques of anaesthesia.

Table 1: Comparison of scores before and after training for Scenarios A,B and C

\begin{tabular}{|ll|c|c|c|}
\hline & & Mean & Standard deviation & P value \\
\hline Pair 1 & A1 & 3.60 & 1.188 & $0.000^{*}$ \\
& A2 & 5.85 & 0.366 & \\
\hline Pair 2 & B1 & 5.50 & 1.987 & $0.000^{*}$ \\
& B2 & 8.80 & 0.834 & \\
\hline Pair 3 & C1 & 4.17 & 0.857 & $0.000^{*}$ \\
& C2 & 5.67 & 0.485 & \\
\hline
\end{tabular}

$\mathrm{P}$ value $<0.05$ is significant

${ }^{\dagger} \mathrm{A} 1$-Before training for scenario A, A2- After training for scenario A,B1- Before training for scenario B,B2- After training for scenario B,C1- Before training for scenario C,C2- After training for scenario C 
Table 2: Comparison of pretraining scores for Scenario A,B and C among all pg levels

\begin{tabular}{|c|c|c|c|c|c|c|c|c|c|c|c|}
\hline \multicolumn{4}{|c|}{ Scenario A } & \multicolumn{4}{|c|}{ Scenario B } & \multicolumn{4}{|c|}{ Scenario C } \\
\hline $\begin{array}{l}\text { (I) } \\
\text { PG } \\
\text { level }\end{array}$ & $\begin{array}{l}(\mathrm{J}) \\
\text { PG } \\
\text { level }\end{array}$ & $\begin{array}{c}\text { Mean } \\
\text { Difference } \\
\text { I-J }\end{array}$ & Significance & $\begin{array}{l}\text { (I) } \\
\text { PG } \\
\text { lev }\end{array}$ & $\begin{array}{l}(\mathrm{J}) \\
\mathrm{PG} \\
\text { level }\end{array}$ & $\begin{array}{c}\text { Mean } \\
\text { Difference }\end{array}$ & $\begin{array}{c}\text { Significan } \\
\text { ce }\end{array}$ & $\begin{array}{l}\text { (I) } \\
\text { PG } \\
\text { leve }\end{array}$ & $\begin{array}{l}\text { (J) } \\
\text { PG } \\
\text { level }\end{array}$ & $\begin{array}{c}\text { Mean } \\
\text { Difference }\end{array}$ & Significance \\
\hline 1 & $\begin{array}{l}2 \\
3\end{array}$ & $\begin{array}{l}-1.69^{*} \\
-2.405^{*}\end{array}$ & $\begin{array}{l}0.001 \\
0.000\end{array}$ & 1 & $\begin{array}{l}2 \\
3 \\
\end{array}$ & $\begin{array}{l}-2.690^{*} \\
-3.976^{*}\end{array}$ & $\begin{array}{l}0.002 \\
0.000\end{array}$ & 1 & $\begin{array}{l}2 \\
3 \\
\end{array}$ & $\begin{array}{l}-1.095^{*} \\
-1.467^{*}\end{array}$ & $\begin{array}{l}0.020 \\
0.004\end{array}$ \\
\hline 2 & $\begin{array}{l}1 \\
3\end{array}$ & $\begin{array}{l}1.690^{*} \\
0.714\end{array}$ & $\begin{array}{l}0.001 \\
0.177\end{array}$ & 2 & $\begin{array}{l}1 \\
3\end{array}$ & $\begin{array}{l}2.690^{*} \\
-1.286\end{array}$ & $\begin{array}{l}0.002 \\
0.156\end{array}$ & 2 & $\begin{array}{l}1 \\
3\end{array}$ & $\begin{array}{l}1.095^{*} \\
0.371\end{array}$ & $\begin{array}{l}0.020 \\
0.977\end{array}$ \\
\hline 3 & $\begin{array}{l}1 \\
2\end{array}$ & $\begin{array}{l}2.405^{*} \\
0.714\end{array}$ & $\begin{array}{l}0.000 \\
0.177\end{array}$ & 3 & $\begin{array}{l}1 \\
2\end{array}$ & $\begin{array}{l}3.976^{*} \\
1.286\end{array}$ & $\begin{array}{l}0.000 \\
0.156\end{array}$ & 3 & $\begin{array}{l}1 \\
2\end{array}$ & $\begin{array}{l}1.467^{*} \\
0.371\end{array}$ & $\begin{array}{l}0.004 \\
0.977\end{array}$ \\
\hline
\end{tabular}

*. The mean difference is significant at the 0.05 level.

Table 3: Comparison of post 4 week training scores for all 3 scenarios between all pg levels

\begin{tabular}{|cc|c|c|}
\hline \multicolumn{2}{|l|}{ PG Level } & Mean Rank & P value \\
\hline A2 & 1 & 7.00 & \\
& 2 & 12.00 & $0.020^{*}$ \\
& 3 & 12.00 & \\
\hline B2 & 1 & 5.17 & \\
& 2 & 12.79 & $0.019^{*}$ \\
& 3 & 12.79 & \\
\hline C2 & 1 & 8.00 & \\
& 2 & 8.64 & 0.188 \\
& 3 & 12.50 & \\
\hline
\end{tabular}

${ }^{*} \mathrm{P}$ value $<0.005$ is significant

Table 4: Improvement in score for Scenario A,B and C among all pg levels

\begin{tabular}{|c|c|c|c|c|c|c|c|c|}
\hline \multicolumn{3}{|l|}{ ADIFF $^{*}$} & \multicolumn{3}{|c|}{ BDIFF $^{*}$} & \multicolumn{3}{|c|}{$\mathrm{CDIFF}^{*}$} \\
\hline PG level & Mean & $\mathrm{P}$ value & PG level & Mean & $\mathrm{P}$ value & PG level & Mean & $\mathrm{P}$ value \\
\hline 1 & 3.50 & \multirow{3}{*}{0.000} & 1 & 5.00 & \multirow{3}{*}{0.000} & 1 & 2.17 & \multirow{3}{*}{0.000} \\
\hline 2 & 2.14 & & 2 & 3.29 & & 2 & 1.14 & \\
\hline 3 & 1.43 & & 3 & 2.00 & & 3 & 1.20 & \\
\hline
\end{tabular}

*ADIFF- Improvement in score for scenario A (A2-A1)

BDIFF- Improvement in score for scenario B (B2-B1)

CDIFF- Improvement in score for scenario C (C2-C1)

Table 5: Comparison of improvement in scores for Scenario A,B and C among all pg levels

\begin{tabular}{|c|c|c|c|c|c|c|c|c|c|c|c|}
\hline \multicolumn{4}{|c|}{ Scenario A } & \multicolumn{4}{|c|}{ Scenario B } & \multicolumn{4}{|c|}{ Scenario C } \\
\hline $\begin{array}{l}\text { (I) } \\
\text { PG } \\
\text { level }\end{array}$ & $\begin{array}{l}(\mathrm{J}) \\
\mathrm{PG} \\
\text { level }\end{array}$ & $\begin{array}{c}\text { Mean } \\
\text { Difference } \\
\text { I-J }\end{array}$ & Significance & $\begin{array}{l}\text { (I) } \\
\text { PG } \\
\text { leve }\end{array}$ & $\begin{array}{l}(\mathrm{J}) \\
\text { PG } \\
\text { level }\end{array}$ & $\begin{array}{c}\text { Mean } \\
\text { Difference } \\
\text { I-J }\end{array}$ & Significance & $\begin{array}{l}\text { (I) } \\
\text { PG } \\
\text { level }\end{array}$ & $\begin{array}{l}(\mathrm{J}) \\
\mathrm{PG} \\
\text { level }\end{array}$ & $\begin{array}{c}\text { Mean } \\
\text { Difference } \\
\text { I-J }\end{array}$ & Significance \\
\hline 1 & $\begin{array}{l}2 \\
3\end{array}$ & $\begin{array}{l}1.357^{*} \\
2.071^{*}\end{array}$ & $\begin{array}{l}0.002 \\
0.000\end{array}$ & 1 & $\begin{array}{l}2 \\
3\end{array}$ & $\begin{array}{l}1.714^{*} \\
3.000^{*}\end{array}$ & $\begin{array}{l}0.005 \\
0.000\end{array}$ & 1 & $\begin{array}{l}2 \\
3\end{array}$ & $\begin{array}{l}1.024^{*} \\
0.967^{*}\end{array}$ & $\begin{array}{l}0.013 \\
0.032\end{array}$ \\
\hline 2 & $\begin{array}{l}1 \\
3 \\
\end{array}$ & $\begin{array}{c}-1.357^{*} \\
0.714 \\
\end{array}$ & $\begin{array}{l}0.002 \\
0.117 \\
\end{array}$ & 2 & $\begin{array}{l}1 \\
3 \\
\end{array}$ & $\begin{array}{l}-1.714^{*} \\
1.286^{*}\end{array}$ & $\begin{array}{l}0.005 \\
0.028 \\
\end{array}$ & 2 & $\begin{array}{l}1 \\
3 \\
\end{array}$ & $\begin{array}{l}-1.024^{*} \\
-0.057 \\
\end{array}$ & $\begin{array}{l}0.013 \\
1.000 \\
\end{array}$ \\
\hline 3 & $\begin{array}{l}1 \\
2\end{array}$ & $\begin{array}{l}-2.071^{*} \\
-0.714\end{array}$ & $\begin{array}{l}0.000 \\
0.117\end{array}$ & 3 & $\begin{array}{l}1 \\
2\end{array}$ & $\begin{array}{l}-3.000^{*} \\
-1.286^{*}\end{array}$ & $\begin{array}{l}0.000 \\
0.028\end{array}$ & 3 & $\begin{array}{l}1 \\
2\end{array}$ & $\begin{array}{l}-0.967^{*} \\
-0.057\end{array}$ & $\begin{array}{l}0.032 \\
1.000\end{array}$ \\
\hline
\end{tabular}

*. The mean difference is significant at the 0.05 level.

\section{Discussion}

Anaesthesia residents who face life threatening events perioperatively, are susceptible to stress and burnout. Life threatening situations being a rarity are difficult to simulate in the intraoperative period. The advent of life-sized simulators provides an opportunity for training and evaluating residents with life-sized mannequins, such that acute diagnosis can be integrated with the ongoing demands of managing a changing medical or surgical condition. ${ }^{[1-4]}$

Simulation laboratories provide a forgiving, safe environment to learn. While a little anxiety helps in learning, excess anxiety undermines the process. Students experience significant stress when required to learn procedures as novices on 
patients. ${ }^{[6]}$ Instructional science has shown that the acquisition of clinical expertise in medicine is governed by the learners' engagement in deliberate practice, a facility afforded by simulation. ${ }^{[7]}$

In addition to technical skills, development of non technical skills is a long forgotten, but essential skill to be learnt .In our study, participants were instructed to verbalise and communicate loudly and clearly, and they were scored for the same in the scoring proforma. Hence the need to develop non technical skills and improve on them were duly emphasized in our study.

Studies have shown that simulation-based training is associated with moderate to large effects for educational outcomes when compared with no intervention, and small to moderate effects when compared with non-simulation instructional approaches (e.g. lectures) ${ }^{[8-10]}$ A systematic review and metaanalysis on the role of Simulator based training reported that simulation in anaesthesiology appears to be more effective than no intervention(except for patient outcomes)and non inferior to non simulation instruction.

Simulation was observed to be effective in terms of improvement in participant's technical and non technical skills such as communicative skills, behavioural skills, confidence and knowledge. ${ }^{[10]}$

Features of Simulator based training that provide effective learning include the provision of feedback, repetitive practice, a range of levels of difficulty, the need to capture clinical variation, a controlled environment, individualized learning and reproducible standardized educational experiences in which learners are active participants not passive bystanders.

A study compared the effectiveness of teaching of general anaesthesia induction to medical students using either full scale simulation or traditional supervised teaching with patients in the operating theatre. This study reported that training in simulated environments confers benefits in terms of formative feedback, and collaborative learning if appropriately structured. ${ }^{[11]}$
Airway management can be challenging and the most important patient safety issue in the practice of anesthesiology. Failure to secure the airway and oxygenate the patient is one of the leading cause of death and legal concerns in anesthesiology. ${ }^{[12-13]}$ It is vital that anesthesiology residents receive the best possible training in airway management. Airway management skills are psychomotor; hence simulation training seems a very suitable way to teach such skills. ${ }^{[14]}$ Regional anesthesia is another vital area of expertise for any anaesthesiologist. Cadaver based training is useful for learning regional anaesthesia techniques but it may not be feasible in all institutions due to non availability of cadavers for study purpose. Simulation is therefore, an effective tool to train anesthesiology residents with the various regional anesthesia techniques.

We also conducted a survey among our residents following the simulation study and it was rated by most of them as highly helpful and satisfactory. The significant improvement in scores after Simulator based training could be attributed to better learning and better retention of skills after training on a simulator. It is reasonable to assume that these residents would be more prepared to effectively translate their knowledge into a logical and orderly sequence of actions.

Participants were able to develop their skills and train in an controlled environment, which helped them acquire more confidence and learn the techniques more precisely and effectively.

This study was conducted on a small group of participants which included the anaesthesiology postgraduate cohort at our institute and its effect on patient outcome was not assessed. Also only basic skills and scenarios such as Endotracheal intubation, Epidural technique and ACLS Scenarios were selected for training these residents who comprised of final years to the newly joined first year residents. The final year residents were already well versed with intubation and epidutal techniques. A higher sample size and inclusion of more complex scenarios would help to further establish the role of simulator based 
training. The better test performance after 4 weeks might be at least partly due to the fact that the same simulator was used for training and testing, and all the groups had the same teacher. This kind of bias is not uncommon in simulated education. ${ }^{[15]}$

The cost of maintaining an anesthesiology simulation lab has a considerable burden on a very cost-conscious system. In addition to the cost there is also the need for training faculty and auxiliary staff.

\section{Conclusion}

Evidence from current studies support the use of simulation as a technique to train anesthesiologists. Simulation training is known to improve not only self-reported confidence but clinical performance as well. ${ }^{[16-18]}$ It is reasonable to hypothesize that the results of improved clinical performance would reflect as better patient outcomes. Further research will reveal whether these promising results with simulation may be applied more generally in anaesthesiology teaching to medical students.

\section{References}

1. Gaba DM: Improving anesthesiologists' performance by simulating reality. ANESTHESIOLOGY 1992; 76:491-4

2. Issenberg SB, McGaghie WC, Hart IR, Mayer JW, Felner JM, Petrusa ER, Waugh RA, Brown DD, Safford RR, Gessner IH, Gordon DL, Ewy GA: Simulation technology for health care professional skills training and assessment. JAMA 1999; 282:861-6.

3. Kapur PA, Steadman RH: Patient simulator competency testing: Ready for takeoff? Anesth Analg 1998; 86:1157-9

4. Murray DJ: Clinical simulation: Technical novelty or innovation in education. Anesthesiology 1998; 89:1-2.

5. Gaba DM. The future vision of simulation in healthcare. Qual Saf Health Care. 2004;13:i2-10.
6. Du Boulay C, Medway C. The clinical skills resource: a review of current practice. Med Educ 1999; 33:185-191.

7. Ericsson KA. Deliberate practice and the acquisition and maintenance of expert performance in medicine and related domains. Acad Med 2004; 79(10 Suppl):S70-S81.

8. Cook DA, Hatala R, Brydges $\mathrm{R}$, et al. Technology-enhanced simulation for health professions education: a systematic review and meta-analysis. J Am Med Assoc 2011; 306: 978-88.

9. Cook DA, Brydges R, Hamstra SJ, et al. Comparative effectiveness of technologyenhanced simulation versus other instructional methods: a systematic review and meta-analysis. Simul Health c 2012; 7: 308-20

10. Lorello G.R,Cook D.A, Johnson R.L et al. Simulation-based training in anaesthesiology: a systematic review and metaanalysis.Br J Anaesth 2014;112(2),231-45

11. Hallikainen, Juhana, Väisänenetal. Teaching anaesthesia induction to medical students: comparison between fullscale simulation and supervised teaching in the operatingtheatre. European Journal of Anaesthesiology (EJA) 2009;26(2):101104.

12. Metzner J., Posner K. L., Lam M. S., Domino K. B. Closed claims' analysis Best Practice \& Research: Clinical Anaesthesiology 2011;25(2):263-276.

13. Peterson G. N., Domino K. B., Caplan R. A., Posner K. L., Lee L. A., Cheney F. W. Management of the difficult airway: a closed claims analysis. Anesthesiology 2005; 103(1):33-39.

14. Schaefer J. J., III Simulators and difficult airway management skills. Paediatric Anaesthesia2004;14(1):28-37.

15. Dalley P, Robinson B, Weller J, Caldwell C. The use of high-fidelity human patient simulation and the introduction of 
new anesthesia delivery systems. Anesth Analg 2004; 99:1737-1741.

16. Paige J., Kozmenko V., Morgan B., et al. From the flight deck to the operating room: an initial pilot study of the feasibility and potential impact of true interdisciplinary team training using highfidelity simulation. Journal of Surgical Education 2007;64(6):369-377.

17. Paige J. T., Kozmenko V., Yang T., et al. High-fidelity, simulation-based, interdisciplinary operating room team training at the point of care. Surgery2009;145(2):138146.

18. Chopra V., Gesink B. J., De Jong J., Bovill J. G., Spierdijk J., Brand R. Does training on an anaesthesia simulator lead to improvement in performance? British Journal of Anaesthesia 1994;73(3):293297. 